\title{
Results of the minimally invasive coronary artery bypass grafting angiographic patency study
}

\author{
Marc Ruel, MD, MPH, ${ }^{a}$ Masood A. Shariff, MD, ${ }^{b}$ Harry Lapierre, MD, ${ }^{a}$ Nikhil Goyal, MD, ${ }^{b}$ \\ Carole Dennie, MD, ${ }^{\mathrm{a}}$ Scott M. Sadel, MD, ${ }^{\mathrm{b}}$ Benjamin Sohmer, MD, ${ }^{\mathrm{a}}$ and Joseph T. McGinn, Jr, MD ${ }^{\mathrm{b}}$
}

Objective: Minimally invasive coronary artery bypass grafting is safe and widely applicable, and may be associated with fewer transfusions and infections, and better recovery than standard coronary artery bypass grafting. However, graft patency rates remain unknown. The Minimally Invasive Coronary Artery Bypass Grafting Patency Study prospectively evaluated angiographic graft patency 6 months after minimally invasive coronary artery bypass grafting.

Methods: In this dual-center study, 91 patients were prospectively enrolled to undergo minimally invasive coronary artery bypass grafting via a $4-$ to $7-\mathrm{cm}$ left thoracotomy approach. The left internal thoracic artery, the ascending aorta for proximal anastomoses, and all coronary targets were directly accessed without endoscopic or robotic assistance. The study primary outcome was graft patency at 6 months, using 64-slice computed tomography angiography. Secondary outcomes included conversions to sternotomy and major adverse cardiovascular events (Clinical Trial Registration Unique identifier: NCT01334866).

Results: The mean age of patients was $64 \pm 8$ years, the mean ejection fraction was $51 \% \pm 11 \%$, and there were 10 female patients $(11 \%)$ in the study. Surgeries were performed entirely off-pump in 68 patients $(76 \%)$. Complete revascularization was achieved in all patients, and the median number of grafts was 3 . There was no perioperative mortality, no conversion to sternotomy, and 2 reopenings for bleeding. Transfusion occurred in 24 patients (26\%). The median length of hospital stay was 4 days, and all patients were followed to 6 months, with no mortality or major adverse cardiovascular events. Six-month computed tomography angiographic graft patency was $92 \%$ for all grafts and $100 \%$ for left internal thoracic artery grafts.

Conclusions: Minimally invasive coronary artery bypass grafting is safe, feasible, and associated with excellent outcomes and graft patency at 6 months post-surgery. (J Thorac Cardiovasc Surg 2014;147:203-9)

Earn CME credits at

http://cme.ctsnetjournals.org

The 5-year results of the Synergy Between Percutaneous Coronary Intervention With Taxsus and Cardiac Surgery (SYNTAX) study and the findings of the Future Revascularization Evaluation in Patients With Diabetes Mellitus: Optimal Management of Multivessel Disease (FREEDOM) trial have recently confirmed that coronary

\footnotetext{
From the University of Ottawa Heart Institute, ${ }^{a}$ Ottawa, Ontario, Canada; and Staten Island University Hospital, ${ }^{\mathrm{b}}$ Staten Island, NY.

Funded in part by a research grant by Medtronic, Inc (Minneapolis, Minn).

Disclosures: M.R. reports lecture fees and grant support from Medtronic. J.T.M. reports lecture fees from Medtronic. All other authors have nothing to disclose with regard to commercial support.

M.R. and J.T.M. are co-principal investigators.

Read at the 93rd Annual Meeting of The American Association for Thoracic Surgery, Minneapolis, Minnesota, May 4-8, 2013.

Received for publication May 23, 2013; revisions received Aug 26, 2013; accepted for publication Sept 10, 2013; available ahead of print Nov 1, 2013.

Address for reprints: Marc Ruel, MD, MPH, University of Ottawa Heart Institute, 40

Ruskin St, Suite 3402, Ottawa, Ontario K1Y 4W7, Canada (E-mail: mruel@ ottawaheart.ca).

$0022-5223 / \$ 36.00$

Copyright (C) 2014 by The American Association for Thoracic Surgery

http://dx.doi.org/10.1016/j.jtcvs.2013.09.016
}

artery bypass grafting (CABG) is the safest and most effective way to achieve myocardial revascularization in patients with triple-vessel coronary artery disease $(\mathrm{CAD})^{1}$ and in diabetic patients with multivessel $\mathrm{CAD}^{2,3}$ In addition, a significant number of patients have single-vessel CAD, most often involving the proximal left anterior descending (LAD) artery, for whom CABG is indicated because of the failure or inability to perform percutaneous coronary intervention or as a result of patient or cardiologist preference. ${ }^{4,5}$

Although CABG is safe and effective, its invasiveness has not appreciably diminished over the last several decades. The majority of CABG operations still involve a median sternotomy and use cardiopulmonary bypass, aortic crossclamping, and cardioplegia to induce cardiac arrest.

Safe, reproducible, and widely applicable ways to perform CABG in a less-invasive manner must be explored and investigated to safely build on the effectiveness of $\mathrm{CABG}$, while decreasing its physical and psychologic trauma. To this end, we have introduced, and developed with wide applicability, minimally invasive cardiac surgery (MICS) CABG. Previous reports from our groups have demonstrated (1) the safety and feasibility of this operation in large numbers ${ }^{6,7} ;(2)$ the reproducibility of performing proximal anastomoses onto the ascending aorta ${ }^{8,9}$; and 


\section{Abbreviations and Acronyms

$\begin{array}{ll}\text { CABG } & =\text { coronary artery bypass grafting } \\ \text { CAD } & =\text { coronary artery disease } \\ \text { CCS } & =\text { Canadian Cardiovascular Society } \\ \text { CTA } & =\text { computed tomography angiography } \\ \text { LAD } & =\text { left anterior descending } \\ \text { LITA } & =\text { left internal thoracic artery } \\ \text { MICS } & =\text { minimally invasive cardiac surgery } \\ \text { MIDCAB } & =\text { minimally invasive direct coronary } \\ & \text { artery bypass } \\ \text { SVG } & =\text { saphenous vein graft }\end{array}$

(3) the advantages of MICS CABG over sternotomy CABG in terms of lesser transfusion of blood products, decreased incidence of chest wound infection, and improved postoperative physical recovery. ${ }^{10}$

Nevertheless, the graft patency results of MICS CABG have so far been largely unknown. Although patency after regular CABG can be high, ${ }^{11}$ possible concerns specific to the MICS CABG operation include its increased technical difficulty, the narrower exposure requiring more precise control of the needle during anastomosis, a more restricted selection of distal target sites, and a less intuitive assessment of optimal graft length, all of which could negatively affect graft patency rates.

Consequently, we designed this prospective cohort study in which patients scheduled to receive MICS CABG by 1 of 2 experienced MICS CABG surgeons were enrolled to undergo operation and followed for 6 months after operation, and subsequently undergo computed tomography angiography (CTA) assessment of the patency of their grafts.

\section{MATERIALS AND METHODS Study Objectives}

The primary objective was to characterize technical success (graft patency of each graft at 6 months) and procedural success in consented patients scheduled to undergo a MICS CABG operation. The secondary objective was the evaluation of major adverse events, defined as major hemorrhage/bleeding requiring surgical intervention, aortic complications, graft vessel revision or subsequent revascularization, transient ischemic attack, cerebrovascular accident, myocardial infarction, or death, at both 30 days and 6 months after MICS CABG.

\section{Study Design and Inclusion/Exclusion Criteria}

The study was a prospective, consecutive patient enrollment, dual-center study. Inclusion criteria included age greater than 18 years and less than or equal to 80 years; nonemergency, first time, single or multivessel CABG suitable for MICS CABG; and left ventricular ejection fraction of more than $30 \%$. Exclusion criteria were previous cardiac surgery; a history of renal insufficiency with creatinine greater than 2 $\mathrm{mg} / \mathrm{dL}$; peripheral or systemic active infection; life expectancy of less than 1 year because of other illness; uncontrolled acute myocardial ischemia; New York Heart Association class IV heart failure symptoms; uncontrolled diabetes mellitus or hypertension; recent cerebrovascular accident (within 90 days before operation); and female gender with childbearing potential.

\section{Operative Procedure}

The operative and technical details of the MICS CABG operation have been published. ${ }^{6,8}$ Briefly, harvest of the left internal thoracic artery (LITA) over its entire usable length and cephalad to the level of the subclavian vein, saphenous vein graft (SVG), or radial artery proximal anastomoses handsewn onto the ascending aorta with a side-biting clamp using 6-0 polypropylene, and distal coronary anastomoses handsewn using 7-0 polypropylene are performed under direct vision, without endoscopic or robotic assistance, through a 4- to 7-cm incision in the left fourth or fifth intercostal space, through which a Thoratrak (Medtronic, Inc, Minneapolis, Minn) rib spreader and a Rultract Skyhook (Rultract, Cleveland, Ohio) retractor are used. If exposure during proximal or distal anastomoses is poor or the patient does not tolerate part of the procedure despite hemodynamic support, including low-dose vasopressors, femoral arterial and venous partial cardiopulmonary bypass (without aortic crossclamping) is used.

\section{Postoperative Management and Outcomes Evaluation}

Patients were treated postoperatively with medical therapy as with conventional CABG via sternotomy, including aspirin, beta-blockers, and anti-cholesterol agents. Patients undergoing MICS CABG with a radial artery graft were prescribed a dihydropyridine calcium channel blocker for 6 months. Patients were followed from enrollment to a minimum of 6 months after discharge from the hospital, and all related adverse events were captured and compiled. Because of the lack of evidence regarding its effects on graft patency, ${ }^{11-13}$ clopidogrel use was left to preferred practice. As such, patients undergoing operation without cardiopulmonary bypass assistance in Ottawa received clopidogrel for 6 months postoperatively, whereas patients operated with pump assistance in Ottawa and all patients at Staten Island did not receive clopidogrel postoperatively.

The primary outcome of the study, graft patency at 6 months, was evaluated by using CTA. Before image acquisition, metoprolol or diltiazem (oral or intravenous) was administered if needed, targeting a heart rate of 65 beats/min or less. Patients also received nitroglycerin 0.6 to $0.8 \mathrm{mg}$ sublingually. An intravenous bi-phasic timing bolus protocol (Staten Island University Hospital: $100 \mathrm{~mL}$ of ioversol injection 74\%; OptiRay 350, Maqlinckrodt Inc, Hazelwood, Mont. University of Ottawa Heart Institute: 15 to $25 \mathrm{~mL}$ of iohexal; Omnipaque GE Healthcare, Princeton, NJ, with 40 $\mathrm{mL}$ of saline solution) was used to measure transit time. Subsequently, a tri-phasic protocol $(100 \%$ contrast, $40 \% / 60 \%$ contrast $/$ saline solution [50 mL], and saline solution [40 mL]) was used to acquire final images. The volume and rate of contrast were adjusted according to the patient's body habitus and scan time. Prospective electrocardiogram-gated images were acquired during an inspiratory breath-hold with a Lightspeed VCT (GE Healthcare, Milwaukee, Wis) $(64 \times 0.625 \mathrm{~mm}$ slice collimation, $350 \mathrm{~ms}$ gantry rotation, $400-800 \mathrm{~mA}, 120 \mathrm{kVp}$ ). Padding duration when used was 100 to $150 \mathrm{~ms}$, and all studies were centered at $75 \% \mathrm{R}-\mathrm{R}$ interval. Images were reconstructed using a slice thickness of $0.625 \mathrm{~mm}$ with an increment of $0.4 \mathrm{~mm}$. Images were reviewed by an experienced coronary CTA radiologist on a workstation (AW 4.1 Advantage, GE Healthcare). In an effort to reduce radiation exposure, scan parameters such as max on $\mathrm{mA}, \mathrm{kVp}$, and $\mathrm{z}$-axis coverage were monitored and adjusted by the CTA radiologist.

Interpretations were performed with axial data sets, maximum intensity projections, or curved multiplanar reconstructions (Figure 1) at the discretion of the radiologist. The degree of graft stenosis was graded and classified according to the Fitzgibbon score, as follows: 


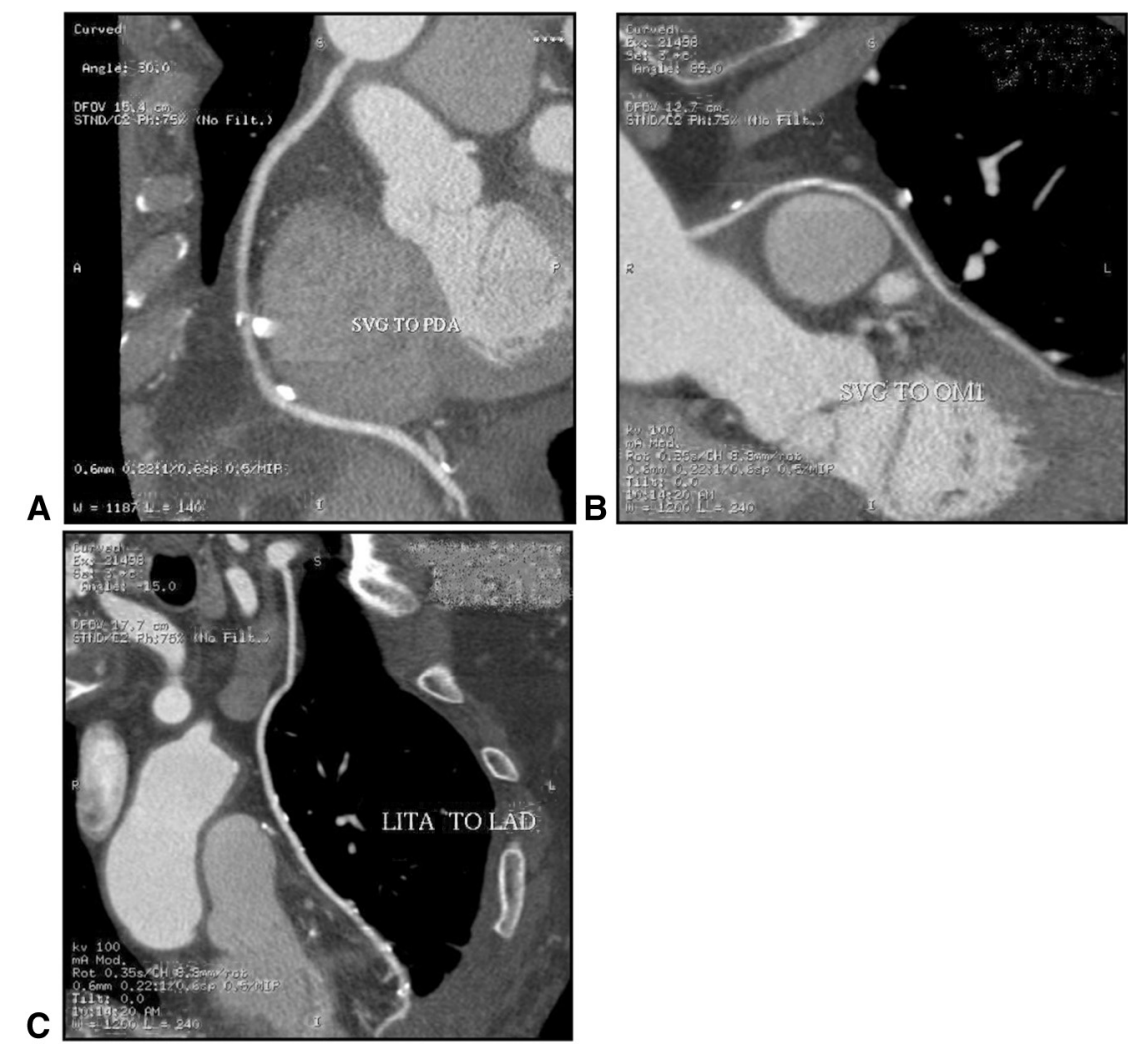

FIGURE 1. Computed tomography reconstruction of grafts performed with MICS CABG. A graft course similar to that seen with conventional CABG is observed. A, Curved multiplanar reconstructed image shows a patent SVG to the posterior descending artery. B, Curved multiplanar reconstructed image demonstrates an SVG to the first obtuse marginal of the left circumflex system. C, Curved multiplanar image of the LITA-LAD. LAD, Left anterior descending; LITA, left internal thoracic artery; OM1, obtuse marginal 1; PDA, posterior descending artery; SVG, saphenous vein graft.

$\mathrm{A}=$ excellent graft with unimpaired runoff, $\mathrm{B}=$ stenosis reducing caliber or distal anastomosis to less than $50 \%$ of the graft, and $\mathrm{O}=$ occlusion. $^{14-16}$

\section{Statistical Analyses}

Results are reported according to the intent-to-treat principle, with patient characteristics described from the time of enrollment and surgical and postoperative outcomes analyzed from beginning of the operation. Continuous data are expressed as means \pm standard deviation, and discrete data are expressed as numbers (percentage). Generalized estimating equations analysis was performed to assess the association of potential clinical predictors with graft Fitzgibbon score at 6 months. Single predictor and multiple predictor models included age, gender, graft conduit (SVG vs LITA), target location (right coronary vs LAD vs circumflex), left ventricular ejection fraction, use of cardiopulmonary bypass, and blood transfusion requirement. For the generalized estimating equations, a Fitzgibbon score of A or B was considered a success and $\mathrm{O}$ was considered a failure. Analyses were performed in SAS version 9.2 (SAS Institute, Inc, Cary, NC).

\section{RESULTS}

Between 2010 and 2012, we enrolled 91 patients with $\mathrm{CAD}$ who were referred for $\mathrm{CABG}$ and scheduled to undergo MICS CABG at Staten Island University Hospital or University of Ottawa Heart Institute. All operations were performed by J. T. M. at Staten Island University Hospital $(\mathrm{N}=46)$ or by $\mathrm{M}$. R. at University of Ottawa Heart Institute $(\mathrm{N}=45)$.
The preoperative characteristics of the patients are shown in Table 1. The patients ranged in age from 44 to 79 years (mean, 64.1 years), and 81 were male. Mean height was

\section{TABLE 1. Preoperative patient characteristics $(\mathbf{N}=91)$}

\begin{tabular}{lc}
\hline Gender, $\mathrm{n}(\%)$ & $10(11 \%)$ \\
Female & $81(89 \%)$ \\
Male & $64.1 \pm 8.3$ \\
Age, mean \pm SD $(\mathrm{y})$ & $81(89 \%)$ \\
Race, Caucasian, $\mathrm{n}(\%)$ & \\
Smoking status, $\mathrm{n}(\%)$ & $16(18 \%)$ \\
Current & $43(47 \%)$ \\
Previous & $32(35 \%)$ \\
Never & $55(60 \%)$ \\
Family history of premature CAD & \\
Medical history & $51.3 \pm 10.8$ \\
LVEF, mean \pm SD (\%) & $16(18 \%)$ \\
Percutaneous coronary intervention & $28(31 \%)$ \\
Myocardial infarction & $2(2 \%)$ \\
Cerebrovascular accident & $27(30 \%)$ \\
Diabetes mellitus requiring treatment & $81(89 \%)$ \\
Hyperlipidemia requiring treatment & $1(1 \%)$ \\
Renal insufficiency & \\
\hline$C A D$, Coronary artery disease; $L V E F$, left ventricular ejection fraction; $S D$, standard \\
deviation.
\end{tabular}


TABLE 2. Perioperative results $(\mathbf{N}=\mathbf{8 9})$

No. of conduits
1
2
3
$>4$

No. of distal anastomoses, median

No. of distal anastomoses, mean $\pm \mathrm{SD}$

Use of cardiopulmonary bypass

Pump assistance without aortic crossclamping Off-pump

Conversion to sternotomy

Incomplete revascularization

Blood transfusion intraoperatively

Ventilation time (intubation to extubation, min), mean \pm SD

Reopening

Blood transfusion postoperatively

Aortic complication, MI, CVA, or death

$21(24 \%)$

$21(24 \%)$

$43(48 \%)$

$4(4.5 \%)$

3.0

$2.3 \pm 0.9$

$21(24 \%)$

$68(76 \%)$

0

0

$5(5.6 \%)$

$538 \pm 255$

$2(2.2 \%)$

$20(23 \%)$

Data are n (\%), unless otherwise stated. CVA, Cerebrovascular accident; $M I$, myocardial infarction; $S D$, standard deviation.

$173 \pm 8 \mathrm{~cm}$ (range, 150-189 cm), and mean weight was 86 $\pm 15 \mathrm{~kg}$ (range, $57-138 \mathrm{~kg}$ ). Eighty-four patients $(92 \%)$ and 37 patients $(41 \%)$ were taking aspirin and clopidogrel, respectively, before the operation. Symptomatic multivessel $\mathrm{CAD}$, present in 68 patients $(75 \%)$, was the most common indication for surgery.

\section{Perioperative Results}

Two patients urgently underwent operation by sternotomy before their scheduled MICS CABG. Of the 89 patients brought to the operating room with the intent to perform MICS CABG, all received the operation without conversion to sternotomy. Table 2 displays the perioperative results. The mean number of grafts was $2.3 \pm 0.9$, and 47 patients $(53 \%)$ received 3 or more grafts. Cardiopulmonary bypass assistance was used in 21 patients $(24 \%)$, with a mean duration of $96 \pm 49$ minutes. A blood product transfusion was required in 24 patients (26\%). Complete revascularization, that is, of each major myocardial territory subtended by a coronary artery of $1.5 \mathrm{~mm}$ or more in diameter with stenosis $70 \%$ or greater, was achieved in all patients.

Two patients $(2.2 \%)$ returned to the operating room for bleeding, and 15 patients $(17 \%)$ had atrial fibrillation. Clopidogrel use had no statistically significant impact on return to the operating room or on blood loss. The median hospital length of stay was 4 days (range, 3-9 days). A left pleural effusion developed in 14 patients $(15 \%)$, none of whom required drainage, and there were no other major adverse events.

\section{Postoperative Results}

Follow-up to 6 months was $100 \%$ complete. None of the patients experienced an aortic complication, repeat
TABLE 3. Adverse events and outcomes at 6 months follow-up

\begin{tabular}{lc}
\hline $\begin{array}{l}\text { Occurrence of study adverse events over 6-mo course of } \\
\text { study }(\mathrm{N}=89)\end{array}$ & \\
Peripheral vascular complication & $14(15 \%)$ \\
Pleural effusion & $15(17 \%)$ \\
Atrial fibrillation & $1(1.1 \%)$ \\
Renal insufficiency & $1(1.5 \%)$ \\
Vein harvest site infection & $2(2.2 \%)$ \\
Superficial chest wound infection & 0 \\
Deep chest wound infection & \\
Primary outcome at 6 mo & $72 / 165$ \\
No. of patients/grafts assessed by CTA & $150(91 \%)$ \\
Fitzgibbon grade A & $1(0.6 \%)$ \\
Fitzgibbon grade B* & $14(8.5 \%)$ \\
Fitzgibbon grade O & $72(100 \%)$ \\
Patent LITA grafts & $76(85 \%)$ \\
Patent SVGs & $151(92 \%)$ \\
Overall graft patency $\dagger$ & \\
\hline Data are $\mathrm{n}(\%)$, unless otherwise stated. CTA, Computed tomography angiography; \\
LITA, left internal thoracic artery; SVG, saphenous vein graft. *In an SVG. $\dagger$ Three \\
of 4 radial grafts used in the study demonstrated Fitzgibbon grade A patency. One \\
radial graft was occluded (grade O).
\end{tabular}

revascularization, myocardial infarction, cerebrovascular accident, or death. Eighty-two patients $(92 \%)$ were free from any degree of angina; 5 patients $(6 \%)$ had Canadian Cardiovascular Society (CCS) class I angina, and 2 patients $(2 \%)$ had CCS class II angina. A total of 5 patients $(6 \%)$ had chest pain that could possibly be related to the thoracotomy, including the 2 patients $(2 \%)$ considered to experience CCS class II angina. Although it seems likely that the cause of the pain in these 2 patients was angina or post-thoracotomy pain, these patients are counted twice (ie, as having both CCS class II and post-thoracotomy pain) because the cause of the chest pain was unclear.

\section{Graft Patency of Minimally Invasive Coronary Artery Bypass Grafting at 6 Months Postoperatively}

The primary outcome of the study (ie, graft patency 6 months after MICS CABG) is described in Table 3. Overall graft patency was 151 of 165 grafts $(92 \%)$ and was $100 \%$ for the LITA and $85 \%$ for SVG $(P<.001$, Fisher exact $)$. A generalized estimating equations model examining the association between graft occlusion and age, gender, left ventricular grade, use of cardiopulmonary bypass, use of clopidogrel, or a requirement for transfusion did not reveal any statistically significant predictor (coefficients not shown).

Curved multiplanar reconstruction images of typical graft configurations to the posterior descending artery (Figure 1,A) and the first obtuse marginal of the circumflex artery (Figure 1, $B$ ) are shown. A typical LITA-LAD reconstruction is shown in Figure 1, $C$.

\section{DISCUSSION}

This prospective study is the first to systematically evaluate and report the patency outcomes of the MICS 
CABG operation. Over the years, a sizable number of these minimally invasive, multivessel CABG operations have been taught, adopted, and performed in the United States, Canada, Italy, India, Japan, and other countries. Consequently, it is important for surgeons who want to perform or appraise this technique to be provided with validated, objective quantification of the efficacy and quality of this procedure. Whether MICS CABG in its current form is applicable to all centers, all surgeons, and all patients remains open to debate, but the key, novel finding of this study is that multivessel coronary revascularization can be performed minimally invasively in a large number of patients with excellent procedural and patency outcomes.

One of the findings in this study was that although overall patency was high at $92 \%$, it was significantly higher for LITA grafts than for SVGs. This has often been noted before and leads to the hypothesis that a hybrid approach combining minimally invasive bypass of the LAD with the LITA constitutes one area where the MICS CABG operation may find its greatest technical approachability, best patency results, and potentially highest institutional applicability, at least during the initial learning curve phase. The availability of MICS CABG may stimulate increased referrals for single-vessel LAD disease, whether approachable by percutaneous coronary intervention or not, ${ }^{6,17}$ because after the results of the FREEDOM trial, controversy may exist with regard to the management of proximal LAD disease in diabetic patients. ${ }^{3}$ In this regard, it is important to note that MICS CABG consisting of single-vessel LITA-LAD is different than the older minimally invasive direct coronary artery bypass (MIDCAB) operation. In this regard, the principles and outcomes of various minimally invasive cardiac procedures were recently reviewed by our group. ${ }^{18}$ With MICS CABG, the incision is more lateral (starting at the mid-clavicular line) than with MIDCAB, the LITA is harvested over its entire cephalad length (up to the subclavian vein) because of the more lateral approach and better exposure, ${ }^{9}$ and the LAD is seen over its entire anterior course, therefore alleviating issues of suboptimal target site selection and error with vessel identification that have been experienced with MIDCAB. Such procedural attributes of MICS CABG may be reflected by the perfect patency observed on the LITA-LAD axis in this study, which to our knowledge has not been reported in a MICS CABG series of this size. This represents a testament to the quality of the MICS CABG operation, making a logical contender to constituting the minimally invasive surgical component of any hybrid revascularization approach. ${ }^{19}$

Last year, the Sternotomy versus Thoracotomy (STET) trial revealed no overall clinical benefit of anterolateral left thoracotomy over median sternotomy on morbidity and health care resource use in patients undergoing off-pump CABG; however, that study did not address the advantages inherent to MICS CABG, namely, reduced transfusion, reduced infection, and reduced time to return to full physical activity. ${ }^{10}$ Our 2 centers have performed MICS CABG in more than 1000 patients with excellent clinical outcomes up to 6 years, ${ }^{7}$ and the present study confirms a mechanistic basis for the favorable outcomes previously observed, ${ }^{6}$ with patency results on par with that of conventional $\mathrm{CABG} .{ }^{20}$

\section{Study Limitations}

This study was performed in 2 centers with expertise and a relatively high adoption rate in $\mathrm{MICS} \mathrm{CABG},{ }^{6}$ which may have led to patient selection and a potential for outcome nongeneralizability, including better results than might otherwise have been observed. The graft patency assessment was performed by using CTA alone, without correlation with invasive angiography. Although less invasive than coronary angiography and sensitive for graft occlusion, the accuracy of coronary CTA for assessing graft stenosis has been shown to be somewhat lower and assessing the adequacy of the distal anastomosis to be problematic if it is of small size. ${ }^{15}$ In addition, assessment of native vessels distal to the anastomosis may prove challenging, and artifacts resulting from the presence of surgical clips along arterial grafts may cause difficulty in image interpretation. Only $81 \%$ of patients returned for CTA; however, this proportion is equivalent to that of other important studies in the field, which reported a follow-up rate of $76 \%$ to $81 \%$ for invasive angiography during the first year. ${ }^{11,20,21}$ Finally, the study reports on relatively short-term major adverse events, and longer-term followup will be necessary to truly ascertain the long-term effectiveness of the MICS CABG operation.

\section{CONCLUSIONS}

Despite the aforementioned shortcomings, the present prospective study constitutes the first to systematically evaluate and report the patency outcomes of multivessel MICS CABG, thereby providing the first true objective measure of the subclinical efficacy of this operation. Although clinical and angiographic results were on par with conventional CABG, further research with regard to the wide applicability of MICS CABG and its comparison with percutaneous interventions and conventional CABG remains to be undertaken.

Our cardiac surgery departments thank the research team members (Jessica Cierzan, Kristin Lawman, and Hang Nguyen) for immense effort in bringing this project together; Dr Wayne Wang for data analysis; our anesthesia colleagues, nursing staff, physician assistants, perfusionists, and critical care team for upholding the highest standards in patient care; and Sarika Naidoo (Ottawa) and Athena DeCarlo (Verrazano Radiology, Staten Island, NY) for patient follow-ups. 


\section{References}

1. Mohr FW, Morice MC, Kappetein AP, Feldman TE, Stahle E, Colombo A, et al. Coronary artery bypass graft surgery versus percutaneous coronary intervention in patients with three-vessel disease and left main coronary disease: 5-year follow-up of the randomised, clinical SYNTAX trial. Lancet. 2013;381:629-38

2. Farkouh ME, Domanski M, Sleeper LA, Siami FS, Dangas G, Mack M, et al Strategies for multivessel revascularization in patients with diabetes. $N$ Engl J Med. 2012;367:2375-84.

3. Farkouh ME, Domanski M, Fuster V. Revascularization strategies in patients with diabetes. $N$ Engl J Med. 2013;368:1455-6.

4. Boodhwani M, Ruel M, Mesana TG, Rubens FD. Minimally invasive direct coronary artery bypass for the treatment of isolated disease of the left anterior descending coronary artery. Can J Surg. 2005;48:307-10.

5. Halkos ME, Vassiliades TA, Myung RJ, Kilgo P, Thourani VH, Cooper WA, et al. Sternotomy versus nonsternotomy LIMA-LAD grafting for single-vessel disease. Ann Thorac Surg. 2012;94:1469-77.

6. McGinn JT Jr, Usman S, Lapierre H, Pothula VR, Mesana TG, Ruel M Minimally invasive coronary artery bypass grafting: dual-center experience in 450 consecutive patients. Circulation. 2009;120(11 Suppl):S78-84

7. McGinn JT Jr, Shariff M, Lapierre H, Sohmer B, Goyal N, Ruel M. Minimally Invasive CABG: results to 6 years. Circulation. 2012;126: A18959 (abstract).

8. Chan V, Lapierre H, Sohmer B, Mesana TG, Ruel M. Handsewn proximal anastomoses onto the ascending aorta through a small left thoracotomy during minimally invasive multivessel coronary artery bypass grafting: a stepwise approach to safety and reproducibility. Semin Thorac Cardiovasc Surg. 2012; 24:79-83.

9. Ruel M, Chan V, Lapierre H, McGinn JT Jr. Multi-vessel small thoracotomy (mvst) coronary artery bypass grafting. In: Sellke FW, Ruel M, eds. Atlas of Cardiac Surgical Techniques. Philadelphia, PA: Elsevier Science; 2009:83-94.

10. Lapierre H, Chan V, Sohmer B, Mesana TG, Ruel M. Minimally invasive coronary artery bypass grafting via a small thoracotomy versus off-pump: a case-matched study. Eur J Cardiothorac Surg. 2011;40:804-10.

11. Kulik A, Le May MR, Voisine P, Tardif JC, Delarochelliere R, Naidoo S, et al. Aspirin plus clopidogrel versus aspirin alone after coronary artery bypass grafting: the clopidogrel after surgery for coronary artery disease (CASCADE) Trial. Circulation. 2010;122:2680-7

12. Chan V, Kulik A, Bourke ME, Ressler L, Mesana TG, Ruel M. Clopidogrel is safe early after on- and off-pump coronary artery bypass surgery. J Card Surg. 2007; 22:493-7.

13. Kulik A, Ruel M. Clopidogrel after coronary artery bypass graft surgery: insufficient evidence. J Am Coll Cardiol. 2011;58:1084-5; author reply 1085-6.

14. Fitzgibbon GM, Kafka HP, Leach AJ, Keon WJ, Hooper GD, Burton JR. Coronary bypass graft fate and patient outcome: angiographic follow-up of 5,065 grafts related to survival and reoperation in 1,388 patients during 25 years. J Am Coll Cardiol. 1996;28:616-26.

15. Mark DB, Berman DS, Budoff MJ, Carr JJ, Gerber TC, Hecht HS, et al. ACCF/ACR/AHA/NASCI/SAIP/SCAI/SCCT 2010 expert consensus document on coronary computed tomographic angiography: a report of the American College of Cardiology Foundation Task Force on Expert Consensus Documents. J Am Coll Cardiol. 2010;55:2663-99.

16. Song MH, Ito T, Watanabe T, Nakamura H. Multidetector computed tomography versus coronary angiogram in evaluation of coronary artery bypass grafts. Ann Thorac Surg. 2005;79:585-8

17. Hoff SJ, Ball SK, Leacche M, Solenkova N, Umakanthan R, Petracek MR, et al. Results of completion arteriography after minimally invasive off-pump coronary artery bypass. Ann Thorac Surg. 2011;91:31-7.

18. Ruel M, Une D, Bonatti J, McGinn JT Jr. Minimally invasive CABG: is it time for the robot? Curr Opin Cardiol. 2013 Sep 26 [Epub ahead of print].

19. Shen L, Hu S, Wang H, Xiong H, Zheng Z, Li L, et al. One-stop hybrid coronary revascularization versus coronary artery bypass graft and percutaneous coronary intervention for the treatment of multivessel coronary artery disease: three-year follow-up results from a single institution. J Am Coll Cardiol. 2013;61:2525-33.

20. Desai ND, Cohen EA, Naylor CD, Fremes SE. A randomized comparison of radial-artery and saphenous-vein coronary bypass grafts. $N$ Engl J Med. 2004; 351:2302-9.

21. Alexander JH, Hafley G, Harrington RA, Peterson ED, Ferguson TB Jr, Lorenz TJ, et al. Efficacy and safety of edifoligide, an E2F transcription factor decoy, for prevention of vein graft failure following coronary artery bypass graft surgery: PREVENT IV: a randomized controlled trial. JAMA. 2005;294: 2446-54

\section{Discussion}

Dr Valavanur Subramanian (New York, NY). Marc, congratulations. Finally you are showing some patency data in the mix. Here is the problem I have. We are now talking about what is the best second arterial graft, because 2 arterial grafts are important for long-term survival. It is a very low-risk group of patients. Now you are advocating minimally invasive multivessel grafting as a standard SVG as a LITA graft. How do you defend your position going forward for the sake of just continuing the SVG in this group of patients?

Dr Ruel. I didn't hear all of your question, but I think you are asking about the second and third arterial grafts. I agree with you; however, there are 3 problems with CABG. First, we have to make it a $0 \%$ mortality operation, and we are close to that, either minimally invasively or open.

Second, we have to try to reach for $100 \%$ patency. We led the Clopidogrel After Surgery for Coronary Artery Disease (CASCADE) Trial before, and I would like to show some discussion slides. Obviously with CASCADE, the 1-year angiographic patency was extremely high. In CASCADE, even the SVG patency in the hands of the Principal Investigators, Pierre Voisine and I, was $96 \%$ at 1 year on angiograms. So this was extremely high. We need to try to reach that confluence where we have a perfect operation with zero risk.

There is a third problem with CABG, and it is its invasiveness, which we also have to work on. What we have shown today is not that MICS CABG is the perfect durable operation. I don't think we have the same results here as when doing LITA, right internal thoracic artery, or radial on everyone, but we certainly have made great strides with regard to decreasing the invasiveness of CABG.

The next step may be to take a right internal thoracic artery down with a robot and give everyone bilateral thoracic arteries. Now that we have shown that the patency of doing a proximal on the aorta through a small incision is high, it is a leap forward toward achieving that goal.

Dr Subramanian. We ought to be honest in comparing patency with a gold standard, angiography, because validation with computed tomography, as you have shown, Fitzgibbon score, and anastomotic quality is not there. So I wish Medtronic had supported you to do a good angiography study with the money involved, and it's important for us to do it.

Dr Ruel. Angiographic quality, first, is something you can look at with computed tomography. It's not always perfect visualization, especially if the heart rate is more than 65 beats/min, but there can be good definition of the anastomosis there. You also have to look at clinical outcomes; there was not a single patient who needed revascularization, so a subradiologic signal, if you will, is unlikely.

I too believe that when you add everything together, computed tomography is not perfect. It actually will make some grafts not easy to evaluate, especially if there are a lot of clips or lots of motion. But angiography is not perfect either and can miss grafts. Again, it is important that we do those patency trials. There is no perfect way to assess patency, but it's important to carry on and do those, in my opinion.

Dr Nikolaos Bonaros (Innsbruck, Austria). The main characteristic of your series is that you construct the proximal 
anastomosis in the aorta and you do not do a Y or T graft. Can you give us some insight as to how you make your decision if you are doing a sequential anastomosis or an anastomosis to the aorta?

Dr Ruel. We described our techniques in other articles, and it is beyond the scope of today's talk, but you are absolutely right. What we generally do is 1 vein graft equals 1 proximal anastomosis, and relatively few sequentials. The configuration one sees on a computed tomography scan essentially is exactly the same as the configuration would be after an open multivessel CABG. There may be a way to maximize the use of sequential grafts with this operation, but you can easily do up to 3 proximal anastomoses on the ascending aorta with this technique.

The other defining feature is not just the proximals. In this series, as you have seen, a lot of posterior descending arteries were grafted, obtuse marginals 3 and 2, and this is another level of minimally invasive applicability that wasn't seen before.

Dr Vivek Rao (Toronto, Canada). Marc, can you just clarify, when you do pump assistance, is it femoral cannulation?

Dr Ruel. It is, yes.

Dr Rao. Any femoral complications from that?

Dr Ruel. No, there were not. Actually in the overall experience, there are now more than 1000 patients in the series by Joe and me, and we haven't had serious peripheral vascular complications from this operation.

These are obviously somewhat selected patients. If I see someone in whom I'm going to do 4 grafts, one of the first things I do in clinic is to make sure that the femoral pulses are nice and bounding, and that we are not going to perform a challenging multivessel MICS CABG in someone who has a 3-mm external iliac vessel. 